\title{
Effect of Dexamethasone on Antepartum Cardiotocography
}

\author{
Ahmed AA, Sayed Ahmed WA and Taha OT* \\ Department of Obstetrics and Gynecology, Suez Canal \\ University, Egypt \\ *Corresponding author: Omima T Taha, Department \\ of Obstetrics and Gynecology, Suez Canal University, \\ Lecturer of Obstetrics and Gynecology, Faculty of \\ Medicine, Round Road, Ismailia 41111, Egypt
}

Received: J anuary 01, 2021; Accepted: January 21, 2021; Published: January 28, 2021

\begin{abstract}
Objective: The purpose of this study was to evaluate the effect of dexamethasone on fetal heart rate parameters using the standard dose regimen.

Study Design: A prospective cohort study conducted in the Maternity Department, Suez Canal University hospitals. Sixty- eight pregnant women with gestational age between 28 and 34 weeks were recruited. Patients received 4 doses of dexamethasone $6 \mathrm{mg}$ every 12 hours for threatened preterm delivery due to preterm premature rupture of membranes, placenta previa or history of preterm labor. Computerized cardiotocography was recorded for 60 minutes on day 0 (before dexamethasone administration), day 2 and day 4 after administration. Cardiotocography monitoring was performed between 11 am and $1 \mathrm{pm}$ to avoid diurnal rhythm of fetal heart rate. Outcome measure included changes in fetal heart rate accelerations, variability and fetal movements following dexamethasone injection.
\end{abstract}

Results: Sixty-eight patients were enrolled in the study. Fetal heart rate accelerations $(P=0.0001)$, short-term variation $(P=0.01)$, episodes of high variation $(P=0.003)$ and fetal movements $(P=0.0001)$ were significantly reduced on day 2 after dexamethasone. No significant changes were found on baseline fetal heart rate $(P=0.18)$, long-term variation $(P=0.1)$ and number of decelerations $(P=0.1)$. All parameters returned to baseline values on Day 4 after administration.

Conclusion: Dexamethasone induces transient suppression of fetal heart rate parameters on day 2 after administration that mimics fetal compromise. Awareness of this phenomenon is important to avoid iatrogenic delivery of preterm fetuses.

Keywords: Antepartum cardiotocography; Dexamethasone

\section{Introduction}

The use of dexamethasone or betamethasone for enhancement of fetal lung maturity is no longer in dispute. There is considerable variation reported between countries and health care practitioners as to which antenatal corticosteroids are commonly used and this is due to the availability and cost differences between dexamethasone and betamethasone. Dexamethasone is less expensive and more widely used in low-income countries [1]. Although betamethasone and dexamethasone are virtually identical pharmacologically, two case series in 1990s have suggested that these drugs have different effects on the antenatal cardiotocography [2]. Dawes et al retrospectively reviewed 28 women who were treated with dexamethasone. On the first day after administration, a significant increase was found in short-term variation of the Fetal Heart Rate (FHR). No changes were seen in basal FHR, or fetal movements [3]. In contrast, Derks et al., prospectively assessed 31 women treated with betamethasone. On the second day after administration significant decreases were found in short- and long-term variation of FHR, as well as fetal movements [4]. Rotmensch et al., in their study concluded that betamethasone and dexamethasone induce a profound, but transient, suppression of FHR characteristics in the preterm fetus. However, the effect of betamethasone was more pronounced [5]. Previous studies on the effect of antenatal corticosteroids on FHR parameters used different dosage regimens and included confounding variables that may cause alterations in FHR patterns as preeclampsia, intrauterine growth retardation and preterm labor. In addition, maternal drug therapy by antihypertensive or tocolytics may interfere with analysis of FHR traces. The aim of this study was to evaluate the effect of dexamethasone on antepartum Cardiotocography (CTG) using the standard dosage regimen recommended by the Royal College of Obstetricians and Gynecologists [6].

\section{Patients and Methods}

This prospective cohort study was conducted at the Maternity Department, Suez Canal University hospitals during the period from June 2017 to January 2019 and was subjected to approval by the research ethics committee of faculty of medicine, Suez Canal University. The study included pregnant women admitted to the department with preterm premature rupture of membranes or placenta previa and those attended antenatal clinic with history of preterm labor. All women fulfilled the following criteria: singleton pregnancy with gestational age between 28 and 34 weeks as calculated by the first day of last menstrual period and confirmed by ultrasound, patients not on drug therapy that may interfere with FHR analysis, reassuring FHR patterns and no uterine contractions on preliminary 


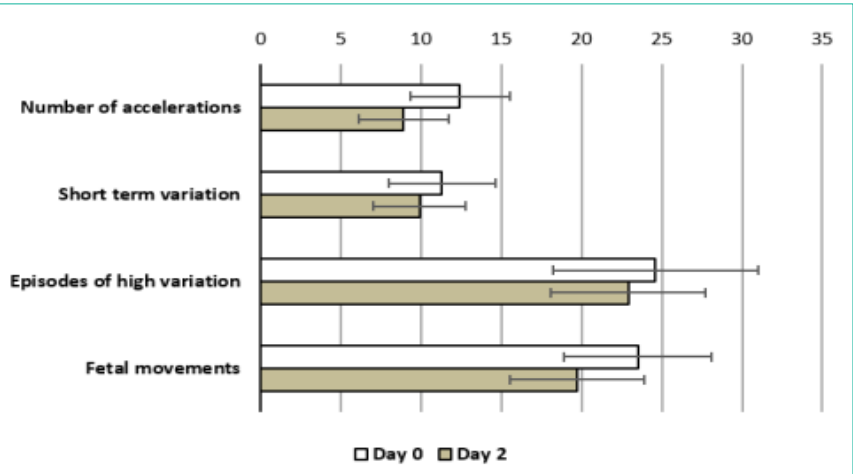

Figure 1: Deviation of CTG parameters from the baseline values on day 2 after dexamethasone.

CTG evaluation. Patients' contents were obtained. Women not candidates for conservative management, congenital fetal anomalies, non-reassuring FHR patterns or who didn't complete the 4 days of evaluation were excluded from the study.

Initial computerized CTG recording Bistos fetal monitor, Med Solutions for 60 minutes duration was obtained before dexamethasone therapy (day 0 ) then all participants received single course of dexamethasone $6 \mathrm{mg}$ intramuscularly 12 hours apart for 4 doses [6]. CTG was then repeated for 60 minutes on day 2 ( $48 \mathrm{hrs}$. later) and day 4 (96 hrs. later) after the first dose of dexamethasone. Every attempt was made to obtain CTG records 2-3 hours after meals between 11 am and $1 \mathrm{pm}$ to avoid diurnal variation of FHR patterns. All patients were monitored in supine, slightly left lateral tilted position to avoid supine hypotension. The patient recorded fetal movements on CTG trace by pressing on the event marker button. Computerized CTG interpretation was made for baseline FHR, short and long-term variability, episodes of high variability, number of accelerations, decelerations and fetal movements. Accelerations $\geq 10 \mathrm{bpm}, \geq 10$ seconds in preterm fetus $<32$ weeks were accepted as normal. Statistical analysis was made by Microsoft excel 2016. Paired $\mathrm{t}$-test was used to compare each variable on day 0 with day 2 , and day 0 with day 4 . Numerical data were presented as means and standard deviations and categorical data as numbers and percentages. P-value $<0.05$ was considered significant.

\section{Results}

Sixty-eight cases fulfilled the inclusion criteria were enrolled in the study. The mean age of the patients was $27.5 \pm 5.3$ years including 16 Nullipara (23.5\%) and 52 multiparas (76.5\%). The indications of dexamethasone administration were preterm premature rupture of membranes (41 cases-60.3\%), placenta previa (16 cases-23.5\%) and previous history of preterm labor (11 cases-16.2\%). The mean gestational age at dexamethasone administration was $31.1 \pm 2.1$ weeks (Table 1). There was no significant difference in the baseline FHR on day 2 and 4 as compared to day 0 after administration of dexamethasone ( $142.7 \pm 10.1$ and $143.8 \pm 9.2$ vs $143.3 \pm 4.4$, respectively, $\mathrm{P}=0.18$ and 0.2 ) (Tables $2 \& 3$ ). There was significant decrease in the number of accelerations $(8.9 \pm 2.8$ vs $12.4 \pm 3.1, \mathrm{P}=0.0001)$, short-term variation $(9.9 \pm 2.9$ vs $11.3 \pm 3.3, \mathrm{P}=0.01)$, Episodes of high variability (22.9 \pm 4.8 vs $24.6 \pm 6.4, \mathrm{P}=0.003)$ and fetal movements $(19.7 \pm 4.2$ vs $23.5 \pm 4.6, \mathrm{P}=0.0001)$ on day 2 after administration of dexamethasone,
Table 1: Descriptive data of the study group.

\begin{tabular}{|l|c|}
\hline & $\mathrm{N}=68$ \\
\hline Age (years) & $27.5 \pm 5.3$ \\
\hline Gestational age at dexamethasone administration (weeks) & $31.1 \pm 2.1$ \\
\hline Parity & \\
\hline Nullipara & $16(23.5 \%)$ \\
\hline Multipara & $52(76.5 \%)$ \\
\hline Indications of dexamethasone & \\
\hline PPROM & $41(60.3 \%)$ \\
\hline Placenta previa & $16(23.5 \%)$ \\
\hline Previous history of PTL ${ }^{* *}$ & $11(16.2 \%)$ \\
\hline
\end{tabular}

"PPROM: preterm premature rupture of membranes

${ }^{*} \mathrm{PTL}$ : preterm labor

as compared to day 0 (Table 2, Figure 1). No significant difference was found regarding long-term variation $(40.9 \pm 7.6 v s 41.1 \pm 9.9, \mathrm{P}=0.1)$ or number of decelerations $(0.9 \pm 1.3$ vs $1.2 \pm 1.3, \mathrm{P}=0.1)$ (Table 2). All CTG parameters returned to pre-exposure values on day 4 with no significant difference as compared to day 0 (Table 3 ).

\section{Discussion}

Synthetic corticosteroids (betamethasone, dexamethasone) are routinely administered to pregnant women with threatened preterm delivery to prevent or reduce complications of prematurity namely respiratory support/intensive care admissions, respiratory distress syndrome, cerebroventricular hemorrhage and necrotizing enterocolitis [7]. Several studies evaluated the effect of antenatal corticosteroids on the FHR parameters with contradictory results. These are partially related to lack of standardization of the steroid dose, time interval between doses and day of CTG evaluation in relation to the day of administration. In addition, it is important to account for possible confounding factors that might also affect the FHR parameters as the use of medication, gestational age, diurnal rhythm and the presence of fetal growth restriction. An important confounder is the use of medications that might influence FHR parameters particularly tocolytic drugs. Although de Heus et al., [8] did not report additional changes in FHR parameters after administration of atosiban or nifedipine, nifedipine might cause fetal tachycardia [9]. Another important medication is antihypertensive drugs used in cases of preeclampsia and pregnancy induced hypertension. The available data are inadequate to draw any conclusions concerning their effect on FHR parameters [10]. Other confounders are the influence of the gestational age and diurnal rhythm. In healthy fetuses between 29-34 weeks gestation, both long-term and short-term variability increase with increase in gestational age whereas baseline FHR decreases $[11,12]$. In addition, a rise in short-term variation and fetal movements and a decrease in the baseline FHR were observed in the afternoon and the evening compared with in the morning [13].

In cases of fetal growth restriction, the baseline FHR is generally higher, and the FHR variability is lower as compared to control group [14]. In addition, Frusca et al., found an even more pronounced decrease in short-term variability on day 3 after administration of betamethasone in fetuses with cerebral vasodilatation. This may be explained by fetal compromise or by a higher concentration of steroids in the fetal brain due to increased cerebral blood flow [15]. In 
Table 2: Computerized CTG parameters on day 0 versus day 2 after dexamethasone.

\begin{tabular}{|c|c|c|c|c|c|}
\hline & Day 0 & Day 2 & & & \\
\hline & & & $P$ value & $95 \% \mathrm{Cl}$ & Mean difference \\
\hline Baseline FHR & \multirow{2}{*}{$143.3 \pm 9.9$} & \multirow{2}{*}{$142.7 \pm 10.1$} & \multirow{2}{*}{0.18} & \multirow{2}{*}{$-0.26-1.35$} & \multirow{2}{*}{0.45} \\
\hline (bpm) & & & & & \\
\hline Number of accelerations & $12.4 \pm 3.1$ & $8.9 \pm 2.8$ & 0.0001 & $2.66-4.37$ & 3.5 \\
\hline Long term variation (msec) & $41.1 \pm 9.9$ & $40.1 \pm 7.6$ & 0.1 & $-0.2-2.26$ & 1.03 \\
\hline Short term variation (msec) & $11.3 \pm 3.3$ & $9.9 \pm 2.9$ & 0.01 & $0.36-2.32$ & 1.34 \\
\hline Episodes of high variation (min) & $24.6 \pm 6.4$ & $22.9 \pm 4.8$ & 0.003 & $0.62-2.91$ & 1.76 \\
\hline Fetal movements & $23.5 \pm 4.6$ & $19.7 \pm 4.2$ & 0.0001 & $2.94-4.67$ & 3.81 \\
\hline Number of Decelerations & $1.2 \pm 1.3$ & $0.9 \pm 1.3$ & 0.1 & $-0.11-0.73$ & 0.31 \\
\hline
\end{tabular}

$\mathrm{bpm}=$ Beats Per Minute, mesc $=$ Milliseconds

Table 3: Computerized CTG parameters on day 0 versus day 4 after dexamethasone.

\begin{tabular}{|c|c|c|c|c|c|}
\hline & \multirow[t]{2}{*}{ Day 0} & \multirow[t]{2}{*}{ Day 4} & \multirow[b]{2}{*}{$P$ value } & \multirow[b]{2}{*}{$95 \% \mathrm{Cl}$} & \multirow[b]{2}{*}{ Mean difference } \\
\hline & & & & & \\
\hline Baseline FHR & \multirow{2}{*}{$143.3 \pm 9.9$} & \multirow{2}{*}{$143.8 \pm 9.2$} & \multirow{2}{*}{0.2} & \multirow{2}{*}{$-1.22-0.22$} & \multirow{2}{*}{-0.5} \\
\hline (bpm) & & & & & \\
\hline Number of accelerations & $12.4 \pm 3.1$ & $13.01 \pm 2.7$ & 0.1 & $-1.04-0.2$ & -0.6 \\
\hline Long term variation (msec) & $41.1 \pm 9.9$ & $40.9 \pm 7.4$ & 0.7 & $-0.8-1.28$ & 0.24 \\
\hline Short term variation (msec) & $11.3 \pm 3.3$ & $10.9 \pm 2.8$ & 0.5 & $-0.64-1.2$ & 0.28 \\
\hline Episodes of high variation (min) & $24.6 \pm 6.4$ & $25 \pm 7.1$ & 0.4 & $-1.2-0.43$ & -0.38 \\
\hline Fetal movements & $23.5 \pm 4.6$ & $22.8 \pm 3.9$ & 0.1 & $-0.26-1.67$ & 0.7 \\
\hline Number of Decelerations & $1.2 \pm 1.3$ & $0.99 \pm 1.2$ & 0.3 & $-0.2-0.64$ & 0.22 \\
\hline
\end{tabular}

bpm= Beats Per Minute, mesc= Milliseconds

the present study we used the standard dosage regimen recommended by RCOG [6]: single course of dexamethasone $6 \mathrm{mg}$ intramuscularly 12 hours apart for 4 doses and to avoid the above-mentioned confounders, only pregnant women with preterm premature rupture of membranes, placenta previa or history of preterm labor and not on any drug known to affect FHR analysis were enrolled in the study. There is debate regarding the effect of dexamethasone and betamethasone on baseline FHR. Several studies demonstrated no significant changes in the basal FHR after administration of betamethasone [4] or dexamethasone $[3,5]$. Other studies demonstrated significant elevation of baseline FHR on day 1 and day 2 in comparison to day 0 after betamethasone administration. On day 3, the FHR baseline returned to pre-exposure values [16]. Mulder et al found a trend toward decrease in baseline FHR on day 1 in more than $50 \%$ of fetuses following 2 doses of dexamethasone [17]. Senat et al., observed that basal FHR changed in opposite directions with an increase during betamethasone and a decrease during dexamethasone courses [18]. Mulder et al found that the trend of baseline FHR changes was significant only in fetuses younger than 27.5 weeks gestation [11]. In the present study, there was no significant difference in the baseline FHR on day 2 and 4 as compared to day 0 after administration of dexamethasone. Our results are consistent with that observed by Dawes et al., [3] and Rotmensch et al., [5]. Derks et al., found significant decreases in short-term variation and long-term variation of FHR, as well as fetal movements after administration of betamethasone [4]. Rotmensch et al., observed a significant and substantial reduction in FHR accelerations, short-term variability and total movement count 48 hours after betamethasone and dexamethasone administration [5].
All parameters returned to baseline values at 96 hours.

Subtil et al., found that antenatal corticosteroids are responsible for two different phases of FHR modifications that do not vary according to the corticosteroid or the dosage regimen with a significant increase in FHR variability and fetal movements on day 1 after treatment and a significant fall in FHR variability and number of accelerations on day 2 and 3 after treatment [19]. These are in contradiction to the results of Rotmensch et al., who observed a significant decrease in FHR variability and the number of accelerations on day 1 and day 2 in comparison to day 0 after administration of betamethasone [16]. On day 3 variability and number of accelerations returned to preexposure values. In the present study, on day 2 after administration of dexamethasone as compared to day 0 , there was a significant decrease in the number of accelerations, short-term variability, episodes of high variability and fetal movements. No significant difference was found regarding long-term variability or number of decelerations. All parameters returned to pre-exposure values on day 4 with no significant difference as compared to day 0 . These results are in agreement with that observed in other studies $[4,5,16]$. The mechanism by which corticosteroids cause a suppression of FHR parameters and biophysical activities can only be speculated upon the following. One hypothesis involves the high affinity of synthetic corticosteroids for the gonadotrophin receptors that are widely expressed in the central nervous system including the brain stem nuclei and when occupied they suppress neuronal activity, thus reducing physical activity [20]. Another explanation is corticosteroid stimulated fetal systemic hypertension that yields a vagally stimulated baroreceptor response with reflex parasympathetic stimulation and sympathetic inhibition 
[21]. The clinician might be confronted with the occasional fetus who displays reduced heart rate variability, lack of accelerations, and reduced limb/body movements and breathing movements following steroid administration. Awareness of the pharmacologic effect of corticosteroids on parameters for the assessment of fetal well-being might prevent unnecessary iatrogenic delivery of preterm fetuses. However, the differential diagnosis between pathophysiologic and pharmacologic effects can be extremely difficult. The optimal mode for the assessment of fetal well-being under these circumstances is yet to be determined [5]. Doppler waveform assessment of fetal vessels might be useful to assess well-being during the steroid course. It might allow differentiating transient iatrogenic changes in FHR parameters from the effect of hypoxemia [22].

Strengths and limitations of the study: the current study evaluated the effect of dexamethasone over four days after administration. The recruited patients had uneventful pregnancies that continued to term. Larger sample would be recommended. Fetal heart rate patterns were not evaluated in patients that had repeated doses of dexamethasone.

\section{Conclusion}

Dexamethasone; with the standard dosage regimen and after exclusion of confounding factors, induces transient suppression of FHR parameters on day 2 after administration that mimic fetal compromise. All parameters returned to baseline values on day 4 after administration. Awareness of this phenomenon is important to avoid iatrogenic delivery of preterm fetuses.

\section{Funding}

This research was funded by the researchers themselves.

\section{References}

1. Brownfoot FC, Caroline A, Philippa M. Different corticosteroids and regimens for accelerating fetal lung maturation for women at risk of preterm birth. The Cochrane Library. 2008.

2. Magee LA, Dawes GS, Moulden M, Rewdman CW. A randomised controlled comparison of betamethasone with dexamethasone: effects on the antenatal fetal heart rate. Br J Obstet Gynaecol. 1997; 104: 1233-1238.

3. Dawes GS, Serra-Serra V, Moulden M, et al. Dexamethasone and fetal heart rate variation. Br J Obstet Gynaecol. 1994; 101: 675-679.

4. Derks JB, Mulder EJ, Visser GH. The effects of maternal betamethasone administration on the fetus. Br J Obstet Gynaecol. 1995; 102: 40-46.

5. Rotmensch S, Liberati M, Vishne TH, Celentano C, Ben-Rafael Z, Bellati U. The effect of betamethasone and dexamethasone on fetal heart rate patterns and biophysical activities. A prospective randomized trial. Acta Obstet Gynecol Scand. 1999; 78: 493-500.

6. RCOG Green-top guideline. Antenatal Corticosteroids to Reduce Neonatal Morbidity and Mortality. 2010: 7
7. Roberts D, Dalziel SR. Antenatal corticosteroids for accelerating fetal lung maturation for women at risk of preterm birth. Cochrane Database Syst Rev. 2006: CD004454

8. de Heus R, Mulder E, Derks J, Visser GHA. The effects of the tocolytics atosiban and nifedipine on fetal movements, heart rate and blood flow. J Matern Fetal Neonatal Med. 2009; 22: 485-490.

9. Chan LW, Sahota DS, Yeung SY, Leung TY, Fung TY, Lau TK, et al. Sideeffect and vital sign profile of nifedipine as a tocolytic for preterm labour. Hong Kong Med J. 2008; 14: 267-272.

10. Waterman E, Magee L, Lim K, Skoll A, Rurak D, von Dadelszen P. Do commonly used oral antihypertensives alter fetal or neonatal heart rate characteristics? A systematic review. Hypertens Pregnancy. 2004; 23: 155169.

11. Mulder EJ, Koenen SV, Blom I, Visser GHA. The effects of antenatal betamethasone administration on fetal heart rate and behaviour depend on gestational age. Early Hum Dev. 2004; 76: 65-77.

12. Lunshof MS, Boer K, Wolf H, Koppen S, Velderman JK, Mulder EJH. Shortterm $(0-48 \mathrm{~h})$ effects of maternal betamethasone administration on fetal heart rate and its variability. Pediatr Res. 2005; 57: 545-549.

13. de Heus R, Mulder EJ, Derks JB, Koenen SV, Visser GHA. Differential effects of betamethasone on the fetus between morning and afternoon recordings. J Matern Fetal Neonatal Med. 2008; 21: 549-554.

14. Nijhuis IJ, ten Hof J, Mulder EJ, Nijhuis JG, Narayan H, Taylor DJ, et al. Fetal heart rate in relation to its variation in normal and growth retarded fetuses. Eur J Obstet Gynecol Reprod Biol. 2000; 89: 27-33.

15. Frusca T, Soregaroli M, Valcamonico A, Scalvi L, Bonera R, Bianchi U. Effect of betamethasone on computerized cardiotocographic parameters in preterm growth-restricted fetuses with and without cerebral vasodilation. Gynecol Obstet Invest. 2001; 52: 194-197.

16. Rotmensch S, Lev S, Kovo M, Efrat Z, Zahavi Z, Lev N, et al. Effect of betamethasone administration on fetal heart rate tracing: a blinded longitudinal study. Fetal Diagn Ther. 2005; 20: 371-376.

17. Mulder EJ, Derks JB, Visser GH. Antenatal corticosteroid therapy and fetal behaviour: a randomised study of the effects of betamethasone and dexamethasone. Br J Obstet Gynaecol. 1997; 104: 1239-1247.

18. Senat MV, Minoui S, Multon O, Fernandez H, Frydman R, Ville Y. Effect of dexamethasone and betamethasone on fetal heart rate variability in preterm labour: a randomised study. Br J Obstet Gynaecol. 1998; 105: 749-755.

19. Subtil D, Tiberghien P, Devos P, Therby D, Leclerc G, Vaast P, et al. Immediate and delayed effects of antenatal corticosteroids on fetal heart rate: a randomized trial that compares betamethasone acetate and phosphate betamethasone phosphate, and dexamethasone. Am J Obstet Gynecol. 2003; 188: 524-531.

20. de Kloet ER, Reul JHMH, Sutanto W. Corticosteroids and the brain. J Steroid Biochem Mol Biol. 1990; 37: 387-394.

21. Ullian ME. The role of corticosteroids in the regulation of vascular tone Cardiovasc Res. 1999; 41: 55-64.

22. Senat MV, Ville Y. Effect of steroids on arterial Doppler in intrauterine growth retardation fetuses. Fetal Diagn Ther. 2000; 15: 36-40. 